\title{
COSTURA DE PRAZERES E REQUEBROS: A INSURGÊNCIA E ATUALIDADE DE FILIPA DE SOUSA
}

\author{
José Pascoal Mantovani* \\ Nathalia Magalhães Vincentin**
}

\section{RESUMO}

Este artigo trata da inquisição de Filipa de Sousa. O problema suscitado é: como transformar o tema de gênero e/ou sexualidade em dispositivo que problematize subjetividades que estão moldadas às estruturas dominadoras? Nesse contexto, qual o papel da religião como instituição prescritiva? É possível potencializar vozes insurgentes? A fundamentação teórica se respaldará em José Carlos Mesquita, Judith Butler e Guacira Louro. Os objetivos são: apresentar a condenação de Filipa de Sousa e o papel da religião vigente em sua sentença; articular situações de misoginia do século XVI e da contemporaneidade; propor estética da existência para corpos insurgentes diante de religiões dominadoras e instituições castradoras. Como resultado, busca-se demonstrar o paralelo da perseguição de Filipa de Sousa com corpos femininos contemporâneos.

Palavras-chave: Filipa de Sousa; Gênero; Constituição de Subjetividade; Religião; Filosofia.

\section{SEWING PLEASURES AND REQUIREMENTS: THE INSURGENCE AND CURRENCY OF FILIPA DE SOUSA}

\section{ABSTRACT}

This article deals with Filipa de Sousa's inquisition. The problem raised is: how to transform the theme of gender and / or sexuality into a device that problematizes subjectivities shaped by dominating structures? In this context, what is the role of religion as a prescriptive institution? Is it possible to enhance insurgent voices? The theoretical

* Doutor em Educação e Mestre em Ciências da Religião pela Universidade Metodista de São Paulo. Graduado em Teologia e Filosofia.

** Graduanda em Psicologia pela Universidade Metodista de São Paulo. Desenvolveu Iniciação Científica com o tema "Construções de papéis: opressão dos gêneros feminino e masculino". 
foundation will be supported by José Carlos Mesquita, Judith Butler and Guacira Lopes Louro. The objectives are: to present the condemnation of Filipa de Sousa and the role of the current religion in his sentence; articulate situations of misogyny from the 16th century and contemporary times; to propose aesthetics of existence for insurgent bodies in the face of dominating religions and castrating institutions. As a result, we seek to demonstrate the parallel of Filipa de Sousa's persecution with contemporary female bodies

Keywords: Filipa de Souza; Gender; Subjectivity Constitution; Religion; Philosophy.

\section{COSTURA PLACERES Y REQUISITOS: LA INSURGENCIA Y MONEDA DE FILIPA DE SOUSA}

\section{RESUMEN}

Este artículo trata de la inquisición de Filipa de Sousa. El problema planteado es: ¿cómo transformar el tema del género y / o la sexualidad en un dispositivo que problematiza subjetividades que se configuran a partir de estructuras dominantes? En este contexto, ¿cuál es el papel de la religión como institución prescriptiva? ¿Es posible realzar las voces insurgentes? La fundamentación teórica contará con el apoyo de José Carlos Mesquita, Judoth Butler y Guacira Lopes Louro. Los objetivos son: presentar la condena de Filipa de Sousa y el papel de la religión actual en su sentencia; articular situaciones de misoginia del siglo XVI y la época contemporánea; proponer una estética de la existencia para los cuerpos insurgentes frente a las religiones dominantes y las instituciones castradoras. Como resultado, buscamos demostrar el paralelo de la persecución de Filipa de Sousa con los cuerpos femeninos contemporáneos.

Palabras llave: Género; Constitución de subjetividad; Religión; Filosofía.

\section{INTRODUÇÃO}

[...] manda açoitar esta mulher por fazer muitas vezes o pecado nefando de sodomia com mulheres, useira e costumeira a namorar mulheres. E que seja degredada para todo o sempre para fora desta capitania. Aceito o flagelo do chicote num deprimente espetáculo de lágrima e de sangue. Por fim, recebeu a ordem de banimento ad eternum da capitania de Salvador da Baía (José Carlos MESQUITA, 2018, p. 146). 
Filipa de Sousa era costureira na colônia portuguesa em pleno século XVI. Casada e alfabetizada, essa mulher é acusada por, além de escrever cartas de amores e requebros, praticar sodomia feminina. Se por um lado seu crime é sintetizado na homoafetividade, por outro lado, sua condenação extrapola qualquer tipo de razoabilidade, haja vista que ela foi exposta e humilhada publicamente; sofreu violência física; perdeu os poucos bens que possuía para pagar a igreja que a inquiria; além de ser expulsa da terra que escolhera para recomeçar a sua vida - Salvador. Sua resistência e oposição diante das normas instituídas resultaram em flagelo e sofrimento, todavia essa derrota circunstancial não suplantou o que essa vítima, vilanizada pelas normas instituídas, se transformaria na contemporaneidade. Ainda que Filipa tenha sido culpabilizada e silenciada pelos poderes estabelecidos de sua época, sua vida é emblemática não apenas para o corpo feminino, mas para todo corpo que vivencia a violência cotidiana simplesmente por se opor às normas instituídas.

Este artigo pretende evidenciar como o imagético misógino perscruta a subjetividade contemporânea, o qual impõe castrações ao corpo feminino. Por mais que o tema do sexo seja ainda tabu na contemporaneidade, pensar e problematizar a sexualidade feminina é ainda mais complexo, haja vista o espectro dogmático que acompanha a subjetividade patriarcal, heterossexual e branca da atualidade. Portanto, o tema da sexualidade feminina está atado a imbróglios ainda mais perturbadores, e para adentrar neste problema a pergunta que acompanhará este artigo será: como transformar o tema de gênero e/ou sexualidade em dispositivo que problematize subjetividades que estão moldadas a estruturas dominadoras e, simultaneamente, potencialize vozes insurgentes?

A pergunta evidencia ao menos dois movimentos, o primeiro relacionado ao devir que o tema de gênero e sexualidade suscitam. Repensar a constituição da subjetividade é colocar em cena as estruturas que perfilam as normas. Estabelecer o aceitável e não aceitável dentro de uma estrutura social. O segundo movimento considera que a subjetividade do indivíduo se articula com fatos sociais os quais são anteriores, exteriores e objetivos ao sujeito (Émile DURKHEIM, 2007). Ainda que 
Judith Butler trilhe por viés destoante à compreensão durkheimiana, este artigo propõe a articulação entre fatos sociais e subjetividade ao considerar esses elementos como valiosos no ato hermenêutico da vida e suplício de Filipa de Sousa como símbolo de mártir e resistência.

Assumir-se lésbica em pleno século XVI, em um Brasil colonizado por dogmas portugueses - exemplos da obsolescência e decadência europeia - demonstra o quanto Filpia de Sousa carrega em sua existência caráter paradigmático de resistência aos sistemas normativos. Retomar a vida desta mulher em pleno século XXI pode ser chave hermenêutica valiosa para interpretar as estruturas misóginas e de perpetuação de violências que são vistas como aspecto ordeiro e "naturais", de uma sociedade organizada que pré-estabelece o moralmente aceito. A condenação de Filipa de Sousa demonstra, inclusive, o quanto a desigualdade social é vetor de perpetuação de injustiças, haja vista que a sua pena só assumiu essa proporção devido à sua vulnerabilidade social.

Em linhas gerais, os objetivos deste texto são: apresentar, a partir da descrição de José Carlos Mesquita (2018), a condenação de Filipa de Sousa como símbolo emblemático de um corpo violentado; articular o sofrimento de Filipa com os diversos tipos de violência que se revelam no cotidiano descritos por Butler (2019), os quais não são enfrentados porque, em grande parte, são ignorados e normalizados pela sociedade; destacar, a partir do viés de Guacira Louro $(2018$; 2019) e Judith Butler (2019) o tabu inerente a sexualidade, principalmente ao que tangencia ao corpo feminino, de modo que axiomas sociais, religiosos, políticos etc. corroboram para a manutenção e produção das opiniões dos atores sociais; por fim, apresentar pistas para a elaboração de estética da existência, este artigo dialoga com o conceito de performance de Judith Butler (2018), em ressonância com a proposição identitária de Guacira Louro (2014).

O resultado deste artigo é demonstrar como casos similares ao de Filipa de Sousa são revividos na contemporaneidade e que é necessário criar meios de denúncia e resistência a fim de que estigmas culturais de morte sejam enfrentados, promovendo constituição de subjetividades dissonantes com as normativas que docilizam a criticidade e castram a autenticidade do sujeito. 


\section{O GOZO FEMININO: CORPOS VIOLENTADOS E RELIGIÃO INQUI- SIDORA}

Sabe-se que Filipa de Sousa foi qualificada nos autos como cristã-velha e costureira; mais do que isso, além de ter uma profissão que potencializava o contato com as mulheres de sua época, possuía elemento que era típico das elites: era alfabetizada (Carmen DIEZ, 2012). Filipa estava à frente de sua época por ser uma mulher letrada em um mundo sem letras. Sua condição emancipada causou incômodos em uma sociedade colonizada, patriarcal e que consolidava, por meio de cultura do medo e ódio, uma religião tirânica e despótica. Este contexto temia movimentos contrários aos dogmas instituídos, tanto que José Carlos Mesquita (2018, p. 133) destaca que "o depoimento de Filipa de Sousa foi perturbador, aos ouvidos do Inquisidor, pela forma realista como descreveu alguns fatos constituintes da inusitada prática de 'sodomia foeminarum"'.

O álibi da sociedade misógina que estava inserida Filipa era respaldado por narrativas transcendentais da religião católica que buscava se fortalecer diante dos contextos de insurgência típicos do século XVI, a saber as Reformas Protestantes e os movimentos judaicos e muçulmanos que se fortaleciam diante do enfraquecimento do catolicismo. A cultura não era apenas misógina, sobretudo suprimia e desprezava a sexualidade feminina. $O$ fato de considerar a relação sexual entre duas mulheres ser um delito menor está relacionado com a ideia de não haver um objeto externo que pudesse penetrar (Isabel BRAGA, 2017). O imagético falocêntrico estava estabelecido, portanto, era necessário postura de emasculação a este sistema inquisidor.

A legitimação inquisidora da Igreja católica está diretamente associada à sua condição de repreensão aos corpos transgressores. Vale destacar a parcimônia na condenação de Filipa em relação a uma de suas amantes, Paula de Siqueira, a qual era esposa de um contador de prestígio de Salvador e, semelhante a Filipa, letrada. A dissonância entre as punições de Filipa e Paula é vista na própria descrição da sentença de Paula de Siqueira:

A leitura da sentença torna claro que foi condenada, em 2 de dezembro de 1591, a ouvir a dita sentença na sé de Salvador e a fazer abjuração de leve suspeita na fé na Mesa do Santo Ofício, tendo ainda 
que cumprir as seguintes penas: ficar em pé com uma vela acesa na mão, durante uma missa de domingo na sé de Salvador; jejuar em três sextas-feiras, rezar uma vez os salmos de David, ler livros espirituais de doutrina católica e vidas de santos - isto é, hagiografias -, e ainda ao pagamento de 50 cruzados para as despesas do Santo Ofício" (Isabel BRAGA, 2017, p. 6).

O catolicismo era moderador dos bons costumes e, sobretudo, guardião dos dogmas que tornam aceitáveis certas posturas e reprováveis outras. O destaque desta citação é que, diferente de Filipa de Sousa, a sentença de Paula está diretamente associada à sua condição financeira e ao seu status social. Por mais que a transgressão destas mulheres fosse vista como inconcebível pela Igreja, é fato que a condição social é fator decisivo na construção da penalidade. Em geral, o grande problema da transgressão de Filipa e suas amantes se dava no âmbito da exclusão do falo pois:

A igreja pouco ou nada sabia acerca do tribadismo. Parecia-lhe perverso ou até mesmo incongruente que duas mulheres se deleitassem sexualmente sem a intervenção falocêntrica do macho. É uma oposição andrógena, muito peculiar na mentalidade sexista da cristandade. Não admira, por isso que no Tribunal do Santo Ofício imperasse uma visão misógina da sexualidade, atribuindo exclusivamente ao homem o direito do desfrute do prazer (José Carlos MESQUITA, 2018, p. 132).

A presença do falo ou de algum objeto que representasse o falo era primordial para a interpretação de que se houve, de fato, pecado, a presença do pênis ou acessório "era decisivo, porque sem penetração não existia a intenção do pecado nefando, cuja delimitação na doutrina católica romana enferma da mentalidade andrógina e da concepção falocêntrica da sexualidade" (José Carlos MESQUITA, 2018, p. 135). Portanto, a narrativa perscrutadora da religião solidificava o imagético que potencializava o masculino e reificava o feminino, haja vista que "a sodomia feminina não fazia sentido, pois que não existindo um instrumento penetrante não poderia consumar-se o nefando nem se concluir a cópula" (José Carlos MESQUITA, 2018, p. 135). 
Judith Butler vai afirmar que tais precedentes cristãos e cartesianos que assimilam “"o corpo' como matéria inerte que nada significa ou, mais especificamente, significa o vazio profano, a condição decaída: engodo e pecado, metáforas premonitórias do inferno e do eterno feminino" (1990, p. 223-224). A autora ainda vai além e afirma que discursos que estabelecem "as fronteiras do corpo serve[m] ao propósito de instaurar e naturalizar certos tabus concernentes aos limites, posturas e formas de troca apropriados, que definem o que constitui o corpo" (1990, p. 226227). Essa estrutura de ideais separatistas e purificadoras, que punem os que rompem com ela, serve para criar uma aparência de ordem no que ela própria denomina como "transgressões" e, consequentemente, exagera as diferenças entre feminino e masculino.

A inquisição no Brasil, assim como em Portugal, tinha como objeto combater o judaísmo. Entretanto, outras finalidades podem ser constatadas, como perseguir e julgar o que consideravam como heresias e desvios da fé, além de, posteriormente, identificar como inimigos sociais, entre outros, os homossexuais - considerando ser pecado capital ajuntamentos carnais reputados desviantes - como sodomia, bestialidade, bigamia, adultério, etc. (José Carlos MESQUITA, 2018).

A acusação sofrida por Filipa pode ser considerada um tanto peculiar por ao menos dois aspectos: primeiro pela dificuldade do Tribunal do Santo Ofício em identificar e categorizar quais eram os crimes cometidos, por conta de uma mentalidade andrógina que considerava a presença do falo indispensável para haver relação sexual, focava-se, assim, num modelo de relação heterossexual, em que a única funcionalidade do sexo era a reprodução; e em segundo, por conta de sua sentença e execução de pena, considerada extremamente mais severa do que em outros casos semelhantes - o açoite público era visto como a mais odiosa e humilhante punição -, o que nos leva a acreditar que fizeram de Filipa uma espécie de exemplo, pois "embora tivesse cometido safismo com várias e diferentes mulheres, ela nunca utilizou instrumento penetrante, que imitasse o membro masculino" (José Carlos MESQUITA, 2018, p. 34).

Ademais, há relatos de que a copulação feminina era bastante comum na região baiana, sendo considerada na Europa uma "brincadeira 
entre mulheres", desde que não se utilizasse objetos que assemelhassem ao falo com intenção de penetração - por isso a insistência, nos depoimentos das amantes de Filipa, em salientar que nunca houve o manuseio de objetos penetrantes (José Carlos MESQUITA, 2018). Esquecem-se os membros do Tribunal do Santo Ofício que o amor entre mulheres, ao contrário do amor heterossexual, é contemplação. Não há luta, nem separação e muito menos vencedores ou perdedores. As carícias são destinadas a recriar-se uma a outra, não de apropriar-se; numa reciprocidade incorporada, ambas são, ao mesmo tempo, sujeito e objeto (Simone de BEAUVOIR, 2016).

A condenação de Filipa expõe a autenticidade de uma mulher que vivenciava seu corpo e seus prazeres sem se intimidar com os poderes instituídos e dominantes. A vivência de sua sexualidade era forma de insurgir. $O$ aspecto emblemático que Filipa assume traz consigo uma duplicidade: é modelo de como o corpo feminino é violentado por se opor às normas estruturantes, e é resiliente ao passo que assume o papel protagonista em resistir e romper com as estruturas constitutivas de seu tempo, ou como destaca Butler, "a categoria do sexo é, desde o início, normativa” (Judith BUTLER, 2019, p. 194), Filipa, portanto, rebela-se a essa regra. A repreensão e condenação que Filipa sofreu está relacionada com a afirmação de Judith Butler ao que se refere a condição do sexo como fenômeno regulatório de corpos, como aponta a autora:

O sexo não apenas funciona como uma norma, mas é parte de uma prática regulatória que produz os corpos que governa, isto é, toda força regulatória manifesta-se como uma espécie de poder produtivo, o poder de produzir - demarcar, fazer, circular, diferenciar - os corpos que ela controla. Assim, o sexo é um ideal regulatório cuja materialização é imposta: esta materialização ocorre (ou deixa de ocorrer) através de certas práticas altamente reguladas. Em outras palavras, o sexo é um construto ideal que é forçosamente materializado através do tempo (Judith BUTLER, 2019, p. 194).

A sanção sofrida por Filipa evidencia este espectro que articula subjetividade e materialidade. Ainda que se soubesse do poder da inquisição em condenar pessoas que contrariasse as normativas estabelecidas, Filipa faz de seu corpo ponto de enfrentamento. Como descreve Louro 
"a insubordinação, o não-acomodamento, a recusa ao ajustamento são algumas das múltiplas formas que a resistência pode assumir" (Guacira LOURO, 2018, p. 87). Filipa não permite que seu corpo se conforme com a normatização imposta pela inquisição. Apropria-se da condição de incompletude da existência humana para fazer de si corpo insurgente, como destaca Butler:

Na verdade, são as instabilidades, as possibilidades de rematerialização, abertas por esse processo, que marca um domínio no qual a força da lei regulatória pode se voltar contra ela mesma para gerar rearticulações que colocam em questão a força hegemônica daquela mesma lei regulatória (Judith BUTLER, 2019, p. 195).

A abordagem de Butler destaca o devir humano como elemento inerente à existência, isto é, a mudança e a transformação são elementos que acompanham o sujeito que é compelido a se estruturar às normatizações que servem como dispositivos para a manutenção da heterossexualidade (Guacira LOURO, 2018). Nessa direção, Louro aponta que a organização desse sistema parte de processo binário, pois "torna-se insuportável (e impensável) a multiplicidade dos gêneros e das sexualidades. Aqueles e aquelas que escapam da sequência e das normas regulatórias arriscam-se, pois, no domínio da abjeção" (Guacira LOURO, 2018, p. 89). Filipa, por se arriscar, tem seu corpo violentado e torna-se símbolo para a contemporaneidade, além de sua inteireza em assumir-se num contexto de morte, muito semelhante ao atual.

O cotidiano é estigmatizado pelos inumeráveis tipos de feminicídios que fazem parte da estrutura sexista dos dias de hoje. Estima-se que mais de 500 mulheres são agredidas por hora no Brasil (JORNAL NACIONAL, 2019), logo, além de reivindicar o papel da mulher e o seu direito de viver sua vida e sexualidade de modo holístico, é necessário enfatizar modos de enfrentamento aos diversos tipos de violência que são normalizadas, bem como culpabilizam a vítima, aproximando-se do caso de Filipa.

É certo que "a sexualidade não é apenas uma questão pessoal, mas é social e política" (Guacira LOURO, 2019, p. 11). Assim, quando Filipa de Sousa extrapola a lógica heterossexual, torna-se vilã de um sistema 
vil. Seu corpo foi usurpado pelo dogmatismo imperial, haja vista que "os corpos são significados pela cultura e são, continuamente, por ela alterados" (Guacira LOURO, 2019, p. 16). O corpo de Filipa é apropriado pelos dominantes, os quais fazem dela tema tabu e corpo de abjeção, perpetuando a lógica da necropolítica'.

\section{CORPOS AUTÊNTICOS: NORMAS E TABUS COMO PRÁTICAS DE MORTE}

A ditadura da autenticidade carrega, em si, elementos contraditórios significativos, pois ao mesmo tempo que exige dos sujeitos autoafirmação, tal asserção não pode extravasar os limites impostos pelas normas instituídas. Tudo o que extrapola tal limiar é denominado como abjeto. É por meio dos tabus que algumas práticas são ignoradas ou execradas. Os tabus são eficientes, na medida que estabelecem os enunciados que podem ser ditos e os que devem ser rejeitados. A sexualidade, bem como o sexo, são temas tabus. Ainda que temas eróticos acompanhem o sujeito contemporâneo, o pudor em narrar ou descrever certas experiências estabelece a maneira como os sujeitos se comportarão e atuarão na sociedade: desejos são silenciados, práticas são dissimuladas, corpos são desprezados.

Tematizar e problematizar o sexo é potencializar a transgressão sobre os limiares que instituem o que pode ou não ser dito, o que é tido como aceitável ou reprovável; é transformar a sexualidade em dispositivo disruptivo, ou seja, é fomentar cessação, aposiopese de cadências estabelecidas, as quais vulgarizam o corpo e suas possibilidades justamente por transformá-lo refém de dogmas cristalizados. Vale destacar que o que se compreende por sexo não é pressuposto imóvel, posto e definido. Ao invés disso, "ele [o sexo] é uma das normas pelas quais alguém simplesmente se torna viável, é aquilo que qualifica um corpo para a vida no interior do domínio da inteligibilidade cultural" (Judith BUTLER, 2019, p. 196) de modo que a constituição do sujeito está diretamente atrelada com o espectro do sexo, ou seja:

Não é o intento deste artigo desenvolver e aprofundar o conceito de necropolítica, entretanto, a definição que se segue aqui está atrelada a noção dos meios pelos quais a morte é efetivada, legalizada e normalizada na contemporaneidade. Como fundamentação teórica está o texto Necropolítica de Achille Mbembe (2018). 
A formação de um sujeito exige uma identificação com o fantasma normativo do sexo: essa identificação ocorre através de um repúdio que produz um domínio de abjeção, um repúdio sem o qual o sujeito não pode emergir. Trata-se de um repúdio que cria a valência da abjeção - e seu status para o sujeito - como um espectro ameaçador (Judith BUTLER, 2019, p. 197).

A proposição de Butler enfatiza que a identidade está entrelaçada com o que determinada sociedade e/ou cultura define como sexo. Ao ordenar e "classificar os sujeitos, toda sociedade estabelece divisões e atribui rótulos que pretendem fixar as identidades. Ela define, separa e, de formas sutis ou violentas, também distingue e discrimina" (Guacira LOURO, 2019, p. 18). Justifica-se, portanto, a demonização e abjeção de alguns corpos por serem antagônicos ao nomos fundacional. Este fenômeno é recorrente em qualquer corpo opositor, todavia, o corpo feminino é mais duramente violentado.

Em uma perspectiva atual, psiquiatras e outros/as profissionais consideram que mulheres homossexuais não são "malditas", mas se constituem como todas as demais mulheres. Como destaca Louro, "os corpos não são, pois, tão evidentes como usualmente pensamos. Nem as identidades são uma decorrência direta das 'evidências' dos corpos" (Guacira LOURO, 2019, p. 17). Hormônios e anatomia não definem uma situação. Não há um destino anatômico que determine a sexualidade. A homossexualidade não é nem uma perversão, nem uma maldição fatal. Entre os/as estudiosos/as, o que é dificultoso em explicar na sexualidade lésbica não é o interesse, em si, por mulheres, mas sim sua exclusividade, além da existência de uma tendência a recusa da passividade (Simone de BEAUVOIR, 2016).

Ao olharmos para a vida de Filipa de Sousa como exemplo, podemos observar que era uma mulher sedutora e que vivia sua sexualidade em liberdade, dessacralizada. Seus encontros eram discretos e desconhecidos pelos familiares das moças envolvidas, "com total desprezo pela matriz masculina” (José Carlos MESQUITA, 2018, p. 21), deixando os inquisidores demasiadamente incomodados. Além disso, em seus depoimentos na presença do inquisidor, Filipa defendeu com veracidade suas preferências sexuais, dizendo amar e sentir grande afeição carnal pelas mulheres 
com quem se relacionou (José Carlos MESQUITA, 2018). A intensidade do depoimento de Filipa contraria o senso comum inquisidor que não ponderava o corpo feminino como corpo que, além de sentir prazer, estava suscetível ao sentimento que, desde antiguidade - a considerar a obra "O Banquete", de Platão (1991) - era restrito ao sexo masculino.

Simone de Beauvoir (2016) vai dizer que a mulher somente se sente diminuída quando escolhe ser um sujeito completo, porque, nas sociedades ocidentais, a feminilidade está vinculada com ser mutilada, castrada. Assim, tal escolha acaba por se confundir com virilidade, com o ser-se masculino; se há uma exacerbação nas atitudes de mulheres lésbicas, é porque viver com naturalidade, para elas, seria impossível, pois "a naturalidade implica não refletir sobre si mesmo, agir sem representar seus atos; mas as condutas de outrem levam sem cessar a lésbica a tomar consciência de si" (Simone de BEAUVOIR, 2016, p. 180).

É preciso ter cautela ao comparar a posição viril assumida por Filipa em sua vida, e no seu testemunho, com uma vontade de imitar o homem, pois corre-se o risco de relegá-la à inautenticidade, ao assumir o homem como positivo e neutro - como se o ser humano estivesse sintetizado no masculino. Toda vez que uma mulher se colocar como sujeito, alegará que ela está identificada com o macho (Simone de BEAUVOIR, 2016). O perigo desse tipo de interpretação reside na naturalização da mulher fazer-se feminina, ou seja, não basta apenas uma tendência à heterossexualidade, ou até mesmo a maternidade, para a mulher ser considerada de verdade, é preciso que ela se torne um produto - artificial - socialmente castrado e docilizado, e, assim, não se torne ameaça ao orgulho fálico (Simone de BEAUVOIR, 2016).

Quando Butler afirma que se certas vidas não são aceitáveis como vidas, desde o início, dentro de determinados enquadramentos epistemológicos, essas vidas jamais serão perdidas, pois nunca foram consideradas vivas "no sentido pleno dessas palavras" (Judith BUTLER, 2009, p. 13). É importante ter isso em mente ao olhar para os dados de pesquisas como a da Associação Brasileira de Gays, Lésbicas, Bissexuais, Travestis, Transexuais e Intersexo (ABGLT) que mostram o Brasil como país líder no ranking mundial em matar pessoas LGBTQIA+ (Daniel CERQUEIRA, 2019). Vale destacar, também, que o Brasil é considerado o país que mais 
consome pornografia com pessoas transgênero e travestis no mundo (Bruna BENEVIDES, 2020). Vemo-nos em uma estrutura terrivelmente individual cuja vida das mulheres, principalmente das mulheres que têm vivências genérico-sexuais desviantes da norma - como lésbicas, mulheres trans e travestis - não são dignas de serem choradas (Judith BUTLER, 2009).

Ainda para Butler, o problema não residiria somente em incluir as pessoas dentro das normas que operam reconhecendo determinados sujeitos e outros não, "mas sim considerar como as normas existentes atribuem reconhecimento de forma diferenciada" (Judith BUTLER, 2009, p. 20). Por este viés, a autora ainda retoma o conceito hegeliano de cena do reconhecimento, em que o sujeito só se reconhece - e é reconhecido - como tal quando há um encontro social, ou seja, é através de encontros entre corpos subjetivos, e através da experiência que nos reconhecemos sujeitos. Porém, ela vai além e afirma que "nem todos os atos de conhecer são atos de reconhecimento" (Judith BUTLER, 2009, p. 21), pois parte do que se reconhece de si está ligado com o reconhecimento identitário que o outro faz de si. Ela defende que é preciso que a vida seja inteligível como uma vida previamente ao ato de reconhecimento. Portanto, para Butler, “[...] da mesma forma que as normas da condição de ser reconhecido preparam o caminho para o reconhecimento, os esquemas de inteligibilidade condicionam e produzem essas normas" (Judith BUTLER, 2009, p. 21).

Como descrito anteriormente, as normas estabelecidas fortalecem a manutenção e perpetuação de tabus, por exemplo, como destaca Gayle Rubin ao tema do incesto, o qual atua como proibição e sanção, impondo um objetivo social de exogamia e dividindo as escolhas sexuais entre permitidas ou não (apud Judith BUTLER, 1990). Para que uma cultura consiga cumprir seu objetivo de manter-se e reproduzir-se a si mesma, também é instituída uma heterossexualidade exogâmica, consequentemente, o tabu do incesto pressupõe um tabu anterior que proíbe, além da união sexual entre parentes, a homossexualidade; assim, o gênero não seria apenas uma identificação com um determinado sexo, mas abarca também um desejo sexual - e que esse desejo seja dirigido para o sexo oposto (Judith BUTLER, 1990). 
O trabalho em situar uma sexualidade que exista antes da lei - como uma bissexualidade primária, defendida na psicanálise -, já implica que a lei é anterior a sexualidade. Gayle Rubin irá defender que as crianças, ao nascerem, possuem "todas as possibilidades sexuais acessíveis à expressão humana” (apud Judith BUTLER, 1990, p. 132), sendo o Édipo modelo que executa tal tabu cultural contra o incesto, pois resulta em distintas - e binárias - identificações de gênero e uma predisposição heterossexual.

O reconhecimento do outro, daquele ou daquela que não partilha dos atributos que possuímos, é feito a partir do lugar social que ocupamos. De modo mais amplo, as sociedades realizam esses processos e, então, constroem os contornos demarcadores das fronteiras entre aqueles que representam a norma (que estão em consonância com seus padrões culturais) e aqueles que ficam fora dela, às suas margens. Em nossa sociedade, a norma que se estabelece, historicamente, remete ao homem branco, heterossexual, de classe média urbana e cristão, e essa passa a ser a referência que não precisa mais ser nomeada (Guacira LOURO, 2018, p. 17-18).

Louro evidencia o quanto valores sociais e estruturas culturais moldam o nomos constitutivo dos indivíduos. As regras disciplinares perscrutam as ações dos sujeitos, ou seja, é por meio da manutenção de instituições hipostasiadas que se garante a manutenção, às avessas, da estética da existência.

O outro não é reconhecido como corpo considerado estranho porque ele desarranja as estruturas postas. Enquanto os axiomas culturais e sociais estabelecerem as normas e regras da existência, os corpos que estão em conformidade serão devidamente rotulados, enquanto que os extravagantes serão cerceados. Filipa foi um corpo que sofreu pela destituição institucional, e, semelhantemente a ela, muitos outros corpos no decorrer da história foram - e continuam a ser - exterminados. Certamente, a constituição dos corpos está sob a égide política, bem como "as formas como elas se representam ou são representadas, os significados que atribuem às suas experiências e práticas é, sempre, atravessado e marcado por relações de poder" (Guacira LOURO, 2018, p. 18-19). Tomar consciência de si pode ser arriscado quando se tem um corpo divergente: 
[...] as coisas se complicam ainda mais para aqueles e aquelas que se percebem com interesses ou desejos distintos da norma heterossexual. A esses restam poucas alternativas: o silêncio, a diminuição ou a segregação. A produção da heterossexualidade é acompanhada pela rejeição da homossexualidade. Uma rejeição que se expressa, muitas vezes, por declarada homofobia (Guacira LOURO, 2018, p. 33).

Filipa de Sousa foi silenciada, diminuída e segregada. Seu corpo foi culpabilizado e submetido a suplícios devido a sua escolha de uma existência autêntica. Sua transgressão confrontava as narrativas colonialistas, patriarcais e eurocêntricas típicas do século XVI. Ainda que a homossexualidade feminina fosse - e ainda o é - vista como tema tabu, a postura de Filipa de Sousa, mais do que confrontar as normas estabelecidas, revelou uma personagem que afirmou suas opções, seus desejos, suas vontades de modo independente, autônomo e consciente. Em pleno período das trevas no Brasil, Filipa se revela como antecipação do período das luzes. Por mais que o imperialismo inquisidor tivesse como prática a violência e até mesmo a morte como instrumento de intimidação, Filipa torna-se emblemática não por ser mártir, mas por ser mulher convicta de si. A partir disso, apresentaremos caminhos de resistência por meio de valores insurgentes.

\section{A ESTÉTICA DA RESISTÊNCIA: CONSTRUÇÃO DE VALORES IN- SURGENTES}

O caminho trilhado neste capítulo foi rememorar a vida e punição de Filipa de Sousa como símbolo de corpo feminino violentado e, assim, evidenciar como a punição e censura acompanham corpos que buscam afirmar sua autenticidade. A proposta desta seção é apresentar, a partir de Filipa de Sousa, a linguagem da resistência para corpos cerceados por enunciados unidimensionais típicos de estruturas heterossexuais dominantes, pois "a normatividade dos gêneros está estreitamente articulada à manutenção da heterossexualidade" (Guacira LOURO, 2018, p. 90). Por exemplo, o caso de Leonard Matlovich é significativo para a compreensão das estruturas de morte e segregação de corpos que se rebelam diante de estruturas dogmatizadas e moralistas. O Jornal do Brasil relata o dia da morte deste ex-combatente, e, mais do que isso, revela os motivos por sua saída das forças armadas americanas: 
Leonard Matlovich (44 anos), ex-sargento da Força Aérea dos Estados Unidos e um dos mais atuantes dirigentes da campanha contra a discriminação que os homossexuais sofrem nas Forças Armadas americanas, morreu de Aids em Los Angeles (California). Em 1975, ao voltar do Vietnã - onde recebera as condecorações de guerra Estrelas de Bronze e o Coração de Púrpura, por sua valentia e heroísmo -, Matlovich fora expulso do serviço militar por haver reconhecido publicamente sua condição homossexual (JORNAL DO BRASIL, 1988, p. 11).

Quase quatro séculos após a condenação de Filipa, o caso de Leonard exemplifica as violências que corpos que transgridem as normas sofrem em sociedades prescritivas. $O$ ato de resistência não é apenas afirmação ideológica. É, sobretudo, um grito de reivindicação do direito de viver. A resistência de Leonard foi se assumir gay em um contexto tiranizado pelo macho; já o ato de resistir de Filipa de Sousa foi assumir-se como corpo emancipado.

A resistência é mais do que pura objeção. É, sobretudo, afirmação identitária, a qual, segundo Butler, é um fenômeno em aberto, ou seja, "compreendemos os sujeitos como tendo identidades plurais, múltiplas; identidades que se transformam, que não são fixas ou permanentes, que podem, até mesmo, ser contraditórias" (Guacira LOURO, 2014, p. 28). Mais do que opor-se às normas regulatórias, o intuito aqui é potencializar a resistência como marca identitária de corpos que destoam dos moldes homogeneizadores. Por resistência, portanto, compreende-se a ideia de corpos insubordinados que assumem o duplo oposição/ performance, ou seja, oposição como égide diante das normas que se efetivam em disciplinas paradigmáticas e performance como intervenção ativa nos vetores constitutivos.

Contrapondo a proposição de que "o corpo é sempre uma corporificação de possibilidades tanto condicionadas quanto circunscritas por convenções históricas" (Judith BUTLER, 2018b, p. 5), é por meio da resistência e seu duplo (oposição/performance) que o sujeito transforma a si mesmo, seu corpo, sua vida em obra de arte, o que é definido, em linguagem foucaultiana, como estética da existência (Michel FOUCAULT, 2018). Compreender a constituição do sujeito a partir desta perspectiva é fomentar a possibilidade de ineditismo que todo corpo carrega em si: 
O corpo não é passivamente roteirizado por códigos naturais, como se fosse um recipiente sem vida de todo um conjunto de relações culturais anteriores. $\mathrm{O}$ 'eu' corporeificado, no entanto, tampouco pré-existe às convenções culturais que dão fundamentalmente significado aos corpos. Os atores estão desde sempre no palco, dentro dos termos da performance. Assim como um roteiro pode ser encenado de diferentes maneiras, e assim como uma peça requer tanto texto quanto interpretação, também o corpo generificado atua em seu papel dentro de um espaço corporal culturalmente restrito, encenando interpretações dentro dos limites diretivos pré-existentes (Judith BUTLER, 2018, p. 11).

A independência de corpos exige insurreição diante das convenções culturais e dogmas cristalizados. Vale destacar que a efetividade de corpos resistentes só se viabilizado por meio da transformação da subjetividade e ressignificação intersubjetiva, ou seja, os valores constitutivos dos indivíduos devem ser alterados a tal ponto que a transgressão se torne o crepúsculo de uma máxima pessoal e política, haja vista que "o pessoal, assim, é implicitamente político, no sentido de que está condicionado por estruturas sociais compartilhadas" (Judith BUTLER, 2018, p. 7). Portanto, a resistência está atada com o processo de ressignificação subjetiva e valorativa. Filipa de Sousa sofre diante dos seus algozes que se mantinham obsoletos em um período renascentista.

As diversas formas de violência contra o corpo feminino foram vulgarizadas pela sociedade. O bombardeio midiático transformou os abusos em acontecimentos ordinários inseridos em um cotidiano que normalizou e banalizou o mal. Neste contexto, a morte e a violência são espetaculares apenas quando assumem o que Muniz Sodré (2009) conceitua como macro acontecimentos, ou seja, fatos extraordinários. As violências contra o corpo feminino garantem a manutenção da lógica cotidiana, do habitual, do costumeiro, de modo que, os micro acontecimentos são ignorados (Muniz SODRÉ, 2009). Em outros termos, as agressões ordinárias do cotidiano, por serem comuns e frequentes a cultura vigente - a qual é habituada com a morte de vidas femininas - converte corpos em algoritmos que conservam as estatísticas de homicídios.

A punição de Filipa só assumiu proporções de julgamento público porque sua amante delatora, Paula de Sequeira, era esposa de um 
homem notável e rico de Salvador, "o certo é que a Mesa da Inquisição optou por fazer de Filipa de Sousa uma espécie de bode expiatório, um exemplo paradigmático do nefando entre mulheres" (José Carlos MESQUITA, 2018, p. 143). Filipa não teve cúmplices. Em vez disso, foi cercada pelos inquisidores.

A condenação, a acusação e a escoriação são formas rápidas de postular uma diferença ontológica entre juiz e julgado, e ainda de se expurgar do outro. A condenação torna-se o modo pelo qual estabelecemos o outro como irreconhecível ou rejeitamos algum aspecto de nós mesmos que depositamos no outro, que depois condenamos. Nesse sentido, a condenação pode contrariar o conhecimento de si, uma vez que moraliza o si-mesmo, negando qualquer coisa comum com o julgado. Embora o conhecimento de si seja certamente limitado, isso não é motivo para rechaçá-lo como projeto. A condenação tende a fazer justamente isso, expurgar e exteriorizar a nossa própria opacidade (Judith BUTLER, 2014, p. 80-81).

Talvez a indignação de seus carrascos tenha sido tamanha justamente por ela se permitir a fruição que era vista como atributo exclusivamente masculino. Sua estética da existência confrontava as pistas e rastros de uma sociedade falocêntrica que, a partir de Filipa de Sousa, fora sobrepujada pelo gozo feminino.

A vida de Filipa não é emblemática apenas por ser um corpo resistente às imposições estruturais. A exemplaridade da vida de Filipa se dá, justamente, por ser um corpo feminino e pobre, que além de sofrer pelos chicotes masculinos, foi vitimado por um sistema intransigente. A violência sofrida por Filipa teve seu ponto nevrálgico em um sistema cruel que a manteve em total solidão, sem cúmplices ou companheiros/ as, rodeada por delatora e acusadores.

Filipa pode ser vista como querela do imagético misógino perscrutador. Seu corpo, estigmatizado pelas normas disciplinares coletivas, é violado e destituído da possibilidade de afirmação identitária. É por essa desidentificação do corpo estranho em relação ao mundo em que está inserido que se legitima a "recontextualização da questão de se saber quais corpos pesam e quais corpos ainda devem emergir como 
preocupações que possam ter um peso crítico"2 (Judith BUTLER, 2019, p. 199). Filipa foi mártir de uma estrutura reificante que classifica o humano pecuniariamente.

A principal vítima deste execrável processo foi a algarvia Filipa de Sousa, sobre quem recaiu a expiação da culpa geral. Não admira, porque era de todas a mais socialmente desprotegida, a mais pobre e insignificante de todas as mulheres arroladas neste vergonhoso processo. (José Carlos MESQUITA, 2018, p. 145).

O julgamento e condenação de Filipa de Sousa não se diferenciam de corpos pobres contemporâneos. Tornar-se cúmplice, hoje, de Filipa é denunciar estruturas que são permeadas pela injustiça social, e fomentar espírito sedicioso em corpos que são cerceados de gozar de sua autenticidade. $O$ paradoxo presente segue a afirmação de Louro ao destacar que "uma matriz heterossexual delimita os padrões a serem seguidos e, ao mesmo tempo, paradoxalmente, fornece a pauta para as transgressões" (Guacira LOURO, 2018, p. 17), portanto são as normas prescritivas que subsidiam corpos resistentes que almejam elaborar valores insurgentes.

Filipa de Sousa personifica corpos que decidem pela autenticidade. Corpos que afirmam a resistência que engloba oposição e performance. Corpos que escolhem fazer da estética da existência palco para o processo de ressignificação, pois "o corpo, portanto, não é uma materialidade idêntica a si mesma ou meramente factual: o corpo é uma materialidade que assume significado, e que assume significado de maneira fundamentalmente dramática" (Judith BUTLER, 2018, p. 4-5). A densidade simbólica de Filipa de Sousa está em sua presença, ainda que com o corpo e gozo reprimido; seu firme posicionamento lança as mais consolidadas convicções e verdades as teias da ambiguidade e indecisão. Por fim, valores insurgentes são aqueles que garantem e afirmam a inteireza, a complexidade e a potência de corpos resistentes.

No original em inglês, a autora vai utilizar-se do termo "matter", traduzido no texto para "peso", os autores, entretanto, acreditam ser mais interessante a tradução para "importar" ou "importância". 


\section{CONSIDERAÇÕES}

A proposição deste texto foi apresentar a vida e suplício de Filipa de Sousa, uma costureira do século XVI no Brasil colônia, que fora foi acusada por enviar cartas de prazeres e requebros a mulheres que se permitiram o transgredir as normas estabelecidas por meio da vivência do gozo feminino. Olhar para Filipa de Sousa é perceber o quanto o corpo feminino é cerceado. A história revela o enrijecimento da sexualidade como tabu, o qual fortalece a manutenção dos sistemas dominadores e opressivos. Filipa, ao aceitar a acusação e, mais do que isso, descrever suas experiências e a intensidade das relações, coloca na berlinda os valores instituídos. Filipa de Sousa é mais do que uma personagem histórica que se rebelou contra os poderes postos, ela é, sobretudo, um corpo que em performance, faz da sua existência a possibilidade para o ato de experienciar a si.

Retomando as perguntas iniciais, a vida de Filipa de Sousa problematiza a normalização das subjetividades que estão moldadas nas estruturas dominantes. Sua punição carrega o duplo referente a negação da razoabilidade, bem como o caráter exemplar que serve como mecanismo de intimidação. Corpos que experimentam a si mesmo destituem a falsa intersubjetividade, a fim de instalar certa intencionalidade de fazer da vida obra de arte. A estética da existência proposta aqui destaca que além da afirmação identitária, é fundamental fortalecer dispositivos de denúncia de estruturas exploratórias. Filipa de Sousa é mais do que mártir, ela, ao descrever sua experiência e rejeitar o imperativo da presença do pênis, rebela-se e, por isso, constitui-se. Por fim, pensar o tema de gênero a partir de Filipa de Sousa é ter a ideia de que estruturas misóginas, sexistas e excludentes são combatidas por meio do confronto com a cultura instituída.

A atuação violenta da Inquisição no Brasil não conseguiu destruir as diversas formas de rejeição da inércia assumida pela performatividade de gênero, muito por conta de mulheres como Filipa que assumiram publicamente e vivenciaram plenamente sua sexualidade - considerada desviante da norma - como uma forma de insubordinação. A importância da releitura de histórias como a de Filipa reside em sua semelhança com casos revividos da contemporaneidade, evidenciando a necessidade da criação de meios de delação para o enfrentamento da necropolítica que castra e dociliza corpos dissonantes da norma, promovendo distintas 
formas de construção das subjetividades.

Atualmente, tais vivências genérico-sexuais distintas ainda encontram-se em situações de vulnerabilidade na sociedade masculinista em que vivemos, muitos homens enxergam como ameaça à sua masculinidade indivíduos transgêneros e mulheres lésbicas; surge, assim, o mito de que essas pessoas poderiam - e deveriam, portanto - ser "curadas" caso se envolvam com um homem "de verdade", tornando justificável - e até essencial para a preservação da sociedade - o que é denominado "estupro corretivo", o que colocaria, as mulheres em seus devidos lugares (Edward BULLOUGH apud Merril SMITH, 2004). Estudos mostram que, mesmo que - independentemente de sua preferência sexual - mulheres são frequentemente mais estupradas, há uma maior probabilidade de acontecer com mulheres lésbicas do que heterossexuais, sendo que, na enorme maioria dos casos, os abusos são perpetuados por homens (Jennifer MANION apud Merril SMITH, 2004).

Ao associar ética e violência, Judith Butler (2015), além de retomar o debate acerca do reconhecimento, questiona o impacto que a violência exerce sobre o enquadramento prévio ao qual a cena de reconhecimento ocorre; assim, aqueles que estão fora dos quadros normativos, não chegam a condição de reconhecimento, não sendo, portanto, vidas passíveis de luto. O fim de Filipa de Sousa é cruel justamente porque ela fazia parte dos corpos que eram exógenos ao quadro normativo. Além de condenada e expulsa de Salvador, por não ser reconhecida por seus pares, nos cabe reconhecer e rememorar seu legado de resistência e constituição identitária, para que seu corpo não seja deixado ao esquecimento.

\section{REFERÊNCIAS}

BRAGA, Isabel Drumond. Leitura e sociabilidade do Feminino: Paula de Sequeira no Brasil Quinhentista. Revista História, v. 36, e. 22, 2017. Disponível em: < https://www.scielo. br/j/his/a/wZ5CYdrmRsptz687JtwNvrJ/?lang=pt\&format=pdf >. Acesso em: 15 jun. 2020.

BEAUVOIR, Simone de. O segundo sexo: a experiência vivida. Rio de Janeiro: Nova Fronteira, 2016.

BUTLER, Judith. Os atos performativos e a constituição do gênero: um ensaio sobre fenomenologia e teoria feminista. Caderno de Leituras, n. 74, 2018. Disponível em: < https://chaodafeira.com/wp-content/uploads/2018/06/caderno_de_leituras_n.78-final. pdf >. Acesso em: 15 jun. 2020. 
BUTLER, Judith. Corpos que pensam: sobre os limites discursivos do sexo. In: LOURO, Guacira Lopes (Org.). O Corpo Educado: Pedagogias da sexualidade. São Paulo: Argos e Autêntica, 2019.

BUTLER, Judith. Problemas de gênero: feminismo e subversão da identidade. Rio de Janeiro: Civilização Brasileira, 1990.

BUTLER, Judith. Quadros de guerra: quando a vida é passível de luto? Rio de Janeiro: Civilização Brasileira, 2009.

BUTLER, Judith. Relatar a si mesmo: crítica da violência ética. São Paulo: Autêntica, 2015. DIEZ, Carmen Lúcia Fornari. Discursos sobre fragilidade feminina: educação da mulher no Brasil colônia. REP - Revista Espaço Pedagógico, v. 19, n. 2, p. 314-324, 2012.

DURKHEIM, Émilie. As Regras do Método Sociológico. São Paulo: Martins Fontes, 2007. FOUCAULT, Michel. Hermenêutica do Sujeito. São Paulo: Martins Fontes, 2018.

LOURO, Guacira Lopes. Gênero, Sexualidade e Educação: Uma perspectiva pós-estruturalista. Petrópolis: Vozes, 2014.

LOURO, Guacira Lopes (Org.). O Corpo Educado: Pedagogias da sexualidade. São Paulo: Argos e Autêntica, 2019.

LOURO, Guacira Lopes. Um Corpo estranho: Ensaios sobre a sexualidade e teoria Queer. São Paulo: Argos e Autêntica, 2018.

JORNAL DO BRASIL. Veterano "gay" morre de aids. Jornal do Brasil. Rio de Janeiro, ano XCVIII, n 78, 25 jun. 1988, 1 caderno, p. 11. Disponível em: < http://memoria.bn.br/ pdf/030015/per030015_1988_00078.pdf >. Acesso em: 10 jun. 2020.

JORNAL NACIONAL. Mais de 500 mulheres são agredidas a cada hora no brasil, diz pesquisa. Jornal Nacional. Disponível em:< https://g1.globo.com/jornal-nacional/noticia/2019/02/26/mais-de-500-mulheres-sao-agredidas-a-cada-hora-no-brasil-diz-pesquisa. ghtml >. Acesso em: 10 de jun. de 2020.

MBEMBE, Achille. Necropolítica. São Paulo: N1 Edições, 2018.

MESQUITA, José Carlos Vilhena. Filipa de Sousa, algarvia condenada na Inquisição pelo "pecado nefando da Sodomia". Revista do Arquivo Municipal de Loulé, n. 20, p. 113-152, 2018.

PLATÃO. O Banquete. São Paulo: Nova Cultural, 1991.

SODRÉ, Muniz. A narração do fato. Rio de Janeiro: Vozes, 2009.

SMITH, Merril D. Encyclopedia of Rape. $1^{\text {a }}$ ed. London: Greenwood Press, 2004.

Submetido em: 30-9-2020

Aceito em: 30-3-2021 